\title{
Antibiotic resistance mechanisms of Helicobacter pylori
}

\author{
Paul S Hoffman PhD
}

\begin{abstract}
PS Hoffman. Antibiotic resistance mechanisms of Helicobacter pylori. Can J Gastroenterol 1999;13(3):243-249. Infection with Helicobacterpylori is most frequently associated with gastritis and peptic ulcer disease. Antimicrobial intervention, together with proton pump inhibitors, has become the standard therapy for treating this disease. Resistance to clarithromycin and metronidazole, two of the most commonly used antimicrobials for treatment of $H$ pylori infections, is often associated with treatment failures and relapse of infection. Clarithromycin resistance arises through mutations leading to base changes in $23 \mathrm{~S}$ ribosomal RNA subunits, while resistance to metronidazole is due to mutations in the $r d x$ A gene, which encodes a novel nitroreductase that is responsible for reductive activation of the drug. Products of metronidazole activation are mutagenic and can be demonstrated to increase both the mutation frequency and the frequency at which antibiotic resistance arises in $\mathrm{H}$ pylori.
\end{abstract}

Key Words: Antibioticresistance, Bismuth, Clarithromycin, Helicobacter pylori, Metronidazole, Nitroreductase

\section{Mécanismes de résistance aux antibiotiques de H. pylori}

RÉSUMÉ : L'infection à H. pylori est le plus souvent associée à la gastrite et à l'ulcère gastro-duodénal. L'antibiothérapie et les inhibiteurs de la pompe à protons sont devenus la norme thérapeutique pour le traitement de cette maladie. La résistance à la clarithromycine et au métronidazole, deux des antibiotiques les plus couramment utilisés pour le traitement des infections à $H$. pylori, est souvent en cause dans les échecs thérapeutiques et les récurrences d'infection. La résistance à la clarithromycine résulte de mutations qui entraînent des changements de bases dans les sous-unités 23S de l'ARN ribosomique, alors que la résistance au métronidazole est due à des mutations $\mathrm{du}$ gène $r d x \mathrm{~A}$ qui encode une nouvelle nitroréductase responsable d'une baisse de l'activation du médicament. Les produits de l'activation du métronidazole sont mutagènes et on a prouvé qu'ils accroissent la fréquence des mutations et la fréquence à laquelle survient la résistance aux antibiotiques en présence d'H. pylori.
A ntibiotic resistance is an ever increasing problem associated with the treatment of most microbial infections including Helicobacter pylori infections, the major cause of gastritis and peptic ulcer disease. Colonization with $\mathrm{H}$ pylori leads to a chronic and often lifelong infection in about $60 \%$ of the world's population (1-3). Chronic infection with $\mathrm{H}$ pylori is an accepted risk factor in the development of gastric cancer, one of the most common malignancies worldwide (4). While most $H$ pylori infections are asymptomatic and the risk for developing more serious disease is estimated at $20 \%$ of infected individuals during a period of 20 years, some investigators believe that $H$ pylori infection should be eradicated through antimicrobial intervention or therapeutic vaccination. Any global effort to eradicate $H$ pylori with antibiotics, however, also has to overcome the substantial problem of drug resistance. In examining the mechanisms of antimicrobial resistance of $\mathrm{H}$ pylori, extrinsic factors must be distinguished from intrinsic ones. Extrinsic factors include extent of infection (microbial load or relative virulence of the strain), immune status of individuals and compliance with treatment regimens. Intrinsic factors include biochemically and genetically based microbial resistance mechanisms. In general, antimicrobial resistance can arise through acquisition of genetic material encoding enzymes that inactivate a particular antibiotic (eg, beta-lactamase, chloramphenicol acetyl transferase or kanamycin phosphotransferase), export antibiotics (eg, tetracycline antiport) or alter the drug

Department of Microbiology and Immunology, Department of Medicine, Division of Infectious Diseases, Dalhousie University, Halifax, Nova Scotia

Correspondence: Department of Microbiology and Immunology, Department of Medicine, Division of Infectious Diseases, Dalhousie University, 7P Sir Charles Tupper Medical Bualding, Dalhousie University, Halifax, Nova Scotia B3H 4H7. Telephone 902-494-3889, fax 902-494-5125, e-mailhoffmanp@tupdean1.med.dal.ca 
target through mutation (eg, penicillin-binding proteins or $23 \mathrm{~S}$ rRNA in macrolide resistance). To date, no plasmidborne antibiotic resistance determinants (ie, extrachromosomal resistance transfer factors) or chromosomal resistance determinants have been found in clinical isolates of $\mathrm{H}$ pylori. Rather, all of the antimicrobial resistance phenotypes described for $\mathrm{H}$ pylori are mutation based (5-9). The lack of antibiotic resistance genes is borne out by DNA sequence analysis of the entire genome of $\mathrm{H}$ pylori strains 26695 (10) and J99 (11). While modern molecular biological tools permit establishing a wide range of antimicrobial resistance phenotypes under laboratory conditions (eg, chloramphenicol or kanamycin resistance), the present review focuses on mutation-based resistance mechanisms that are of clinical importance.

\section{ANTIMICROBIAL SUSCEPTIBILITY}

In vitro, $H$ pylori strains are generally susceptible to penicillins (amoxicillin), cephalosporins, macrolides (clarithromycin), tetracyclines, nitroimidazoles, nitrofurans, furazolidone, nitrothiazoles, quinolones, bismuth salts and even proton pump inhibitors (PPIs) that are commonly employed in combination therapies $(12-15)$. However, monotherapies with these drugs are poorly successful in eradicating infection $(3,16,17)$. The bacterium displays intrinsic resistance to vancomycin, trimethoprim and polymyxin $B(1,7,18)$. However, in vitro susceptibilities do not always correlate with in vivo susceptibilities.

No standard method for determining the antimicrobial susceptibility of $H$ pylori strains exists. Variable results are often attributed to poor growth of strains, variations in laboratory technique or simply lack of clear breakpoints (ie, no bimodal distribution) for resistance among the various testing methods (eg, agar dilution, epsilometer test or tube dilution) $(1,18)$. This is particularly true for the assessment of metronidazole susceptibility, which can have a profound effect on therapy. In vitro resistance to metronidazole (greater than $8 \mu \mathrm{g} / \mathrm{mL}$ ) correlates with decreased efficiency of therapies containing this drug and often leads to treatment failure $(19,20)$. Frequently, retesting the metronidazole susceptibility of strains (an approach that is not practical in a clinical diagnostic laboratory) can reliably resolve intermediate resistance ( 4 to 8 $\mu \mathrm{g} / \mathrm{mL}$ ) to either susceptibility or resistance.

\section{EXTRINSIC FACTORS AFFECTING ANTIBIOTIC BIOACTIVITY}

The site of colonization and pathology of $H$ pylori infection mitigate against some antibiotics that display in vitro efficacy. In this regard, $H$ pylori is a noninvasive pathogen for which the majority of bacteria observed in gastric biopsy material are located in the gastric mucous layer (1). This 'offshore' location may be difficult for antibiotics to reach and together with the constant turnover of the gastric mucus may affect achievement of therapeutic levels. Gastric $\mathrm{pH}$ also affects bioactivity and stability of antibiotics (eg, ampicillin). The antimicrobial susceptibility of $H$ pylori may be altered in situ in response to environmental cues that alter the expression of genes that increase resistance to various antimicrobials. For example, acid shock leads to preferential synthesis of several proteins including heat shock (stress) proteins and CagA $(1,21)$.

\section{RECOMMENDED TREATMENTS}

Based on the findings of several studies, currently recommended therapies for the eradication of $H$ pylori infection often include a PPI (omeprazole, lansoprazole or pantoprazole) together with clarithromycin and either metronidazole or amoxicillin $(17,20)$. Success rates for cure with the use of these combination therapies range from $85 \%$ to $95 \%$. However, resistance to metronidazole or clarithromycin results in an increased failure rate of these therapies as well as of therapies containing omeprazole, bismuth salt, metronidazole and tetracycline; bismuth salt, metronidazole and tetracycline; and ranitidine bismuth citrate plus clarithromycin $(17,18,20)$.

Amoxicillin resistance in $\mathrm{H}$ pylori has been reported at meetings, but other studies have not found resistant isolates from patients (17). The inclusion of a PPI with clarithromycin and metronidazole or clarithromycin and amoxicillin significantly increases the successful eradication of $\mathrm{H}$ pylori. It has been suggested that the increased $\mathrm{pH}$ of the stomach contributes to the increased activity of the antimicrobials against $H$ pylori $(1,18,20)$. It is also possible that increased $\mathrm{pH}$ leads to differences in gene expression by the bacteria or migration of the bacteria to sites where the antimicrobials are more effective. These areas warrant further investigation.

\section{ANTIBIOTIC RESISTANCE MECHANISMS IN H PYLORI}

With the recent finding that mutations in a gene encoding an oxygen-insensitive NADPH nitroreductase are responsible for metronidazole resistance of $\mathrm{H}$ pylori (5), all of the antibiotic resistance mechanisms described so far for $\mathrm{H} p y$ lori can be attributed to mutations in specific genes. That transition base mutations are common in $\mathrm{H}$ pylori and that these mutations are mostly responsible for drug resistance are themes of the present review. Transition base mutations are purine to purine or pyrimidine to pyrimidine (cytosine $\rightarrow$ thymine or adenine $\rightarrow$ guanine) conversions rather than transversion mutations (purine to pyrimidine).

\section{QUINOLONE RESISTANCE}

Several studies have suggested that quinolones such as ciprofloxacin can be used in combination therapy to treat $H$ pylori infection (6). In Escherichia coli, mutations in the DNA gyrase gene (gyrA) confer resistance to quinolones (22). A polymerase chain reaction-based analysis of the gyrA gene of ciprofloxacin-resistant mutants of $H$ pylori revealed mutations in four locations that resulted in amino acid substitutions (6). These included substitutions at amino acid 87 (asparagine $\rightarrow$ lysine), amino acid 88 (alanine $\rightarrow$ valine) and amino acid 91 (aspartate $\rightarrow$ 
glycine, asparagine or tyrosine), and a double substitution at amino acids 91 and 97 (alanine $\rightarrow$ valine). The gyrA amplicons from ciprofloxacin-resistant strains readily transformed sensitive strains to resistant ones indicating that these mutations were sufficient to confer resistance to ciprofloxacin. The $H$ pylori gyrA gene $(10,478$ nucleotides) encodes a protein of 826 amino acids that exhibits $52 \%$ identity with other bacterial gyrA genes and is closely related to the gyrA gene of Campylobacter jejuni $(76.5 \%$ identity) (23). Because of the high frequency of resistance, quinolones are not recommended for use in the treatment of $\boldsymbol{H}$ pylori infections.

\section{BISMUTH RESISTANCE}

Bismuth was one of the early drugs used in triple therapy regimens to treat $H$ pylori infection (16). Anecdotal evidence suggested that for some individuals bismuth subsalicylate (BSS) or colloidal bismuth subcitrate (CBS) could effect a cure (16). However, it is estimated that bismuth salts alone have less than a $10 \%$ success rate of curing infection. Therefore, they are not recommended as a monotherapy $(16,24)$.

In the laboratory, bismuth salts (BSS and CBS) inhibit the growth of $\mathrm{H}$ pylori strains, with minimal inhibitory concentration (MIC) values ranging from 4 to $16 \mu \mathrm{g} / \mathrm{mL}$ (19). A systematic series of heterocyclic bismuth sulphur compounds of known chemical structure that exhibit greater in vitro activity against $H$ pylori than either CBS or BSS has been developed (25). Such studies should lead to the development of more efficacious bismuth compounds for the treatment of gastrointestinal infections. One advantage of the use of bismuth as an antimicrobial is that the metal is highly toxic to selected bacteria, and resistance has not been demonstrated $(19,25)$. Bismuth, a heavy metal, is highly reactive with the thiol groups of proteins and quickly forms complexes that usually lead to inactivation of enzymatic activity. This is particularly relevant for thiol-containing electron carriers and redoxactive compounds found in the membranes of bacteria (26). Preliminary studies in the author's laboratory establish that bismuth complexes become internalized into cytoplasmic inclusions in $\mathrm{H}$ pylori, as determined by electron microscopic examination of sectioned bacteria (Figure 1) (unpublished data).

\section{CLARITHROMYCIN RESISTANCE}

Of the macrolides (erythromycin and azithromycin), clarithromycin is highly effective when used in combination therapy at eradicating $\mathrm{H}$ pylori infection. As a monotherapy, clarithromycin is only $34 \%$ successful (27), and, when metronidazole but not amoxicillin is added, the effectiveness increases up to around $70 \%$ (28). Use of PPIs in combination with either metronidazole or amoxicillin increases the effectiveness, with up to $85 \%$ to $95 \%$ eradication (20).

Resistance to clarithromycin generally parallels the

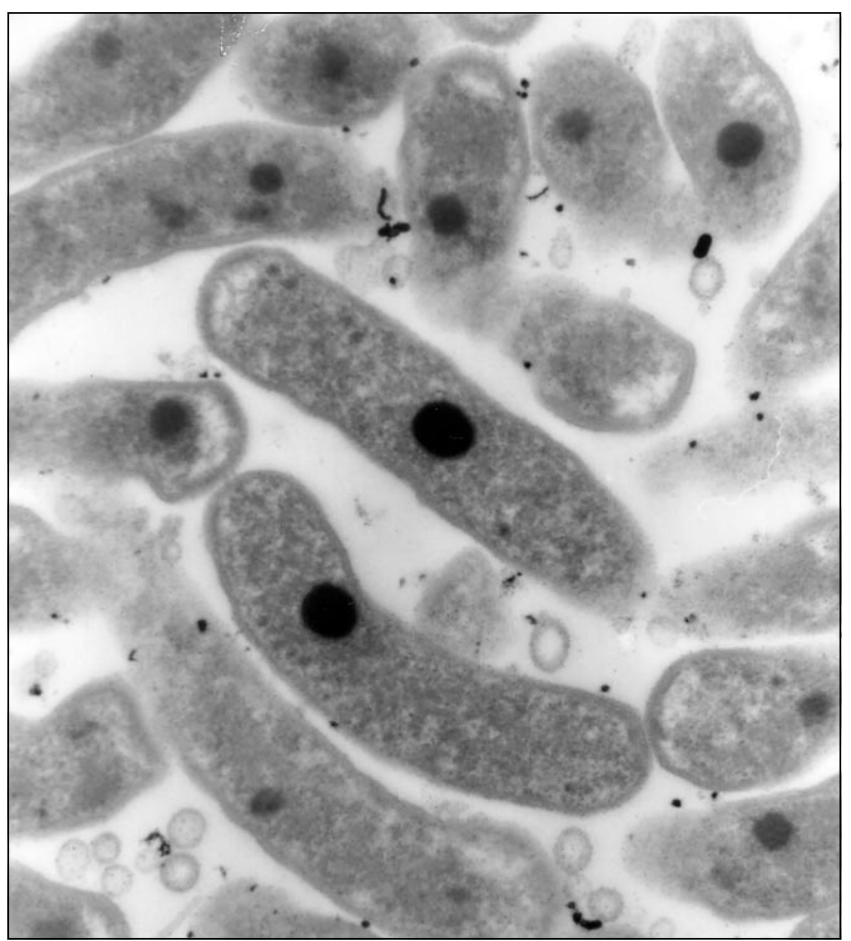

Figure 1) Electron micrograph of an ultrathin section of Helicobacter pylori following treatment with a bismuth-containing salt. The large inclusions in the cytoplasm contain bismuth. Original magnification 37, 300x

level of use of macrolides in a particular region. In North America, resistance to clarithromycin is estimated at $1 \%$ to $4 \%$, whereas, in France and Belgium, the incidence is as high as $10 \%(17,18)$. In Canada, the prevalence is less than $3 \%$. Interestingly, the prevalence of clarithromycinresistant $\mathrm{H}$ pylori isolates from individuals treated with the antibiotic but in whom treatment failed to eradicate the infection varied from $20 \%$ to $60 \%(29,30)$.

Generally, the resistance mechanism for macrolides is similar and involves mutations in the $23 \mathrm{~S}$ subunit of ribosomal RNA (14). In E coli, transition base mutations at positions 2058 (adenine $\rightarrow$ guanine) and 2059 (adenine $\rightarrow$ guanine) confer resistance to clarithromycin. In $\mathrm{H}$ pylori, these positions appear at 2142 and 2143. Several groups have demonstrated that transition base mutations (adenine $\rightarrow$ guanine) at these positions correlate with clarithromycin resistance $(7,8)$. Work by Taylor et al $(7)$ and confirmed by genomic sequence data indicates that there are two copies of the $23 \mathrm{~S}$ ribosomal RNA in $\mathrm{H}$ pylori. In elegant pulsed field gel electrophoresis studies, Taylor et al (7) demonstrated that for most strains of $\mathrm{H}$ pylori, mutations occur in both $23 \mathrm{~S}$ rRNA copies. If the mutations are heterozygous, intermediate resistance to clarithromycin is observed. One recent report indicated that a transversion mutation at position 2143 (adenine $\rightarrow$ cytosine) results in high level resistance to clarithromycin (31). Figure 2 shows the relative position of these substitutions in the $\mathrm{V}$ region of the 23S rRNA subunits for $\mathrm{H}$ pylori. Transition base mutations at position 2142 (adenine $\rightarrow$ guanine) are more likely to occur in isolates 


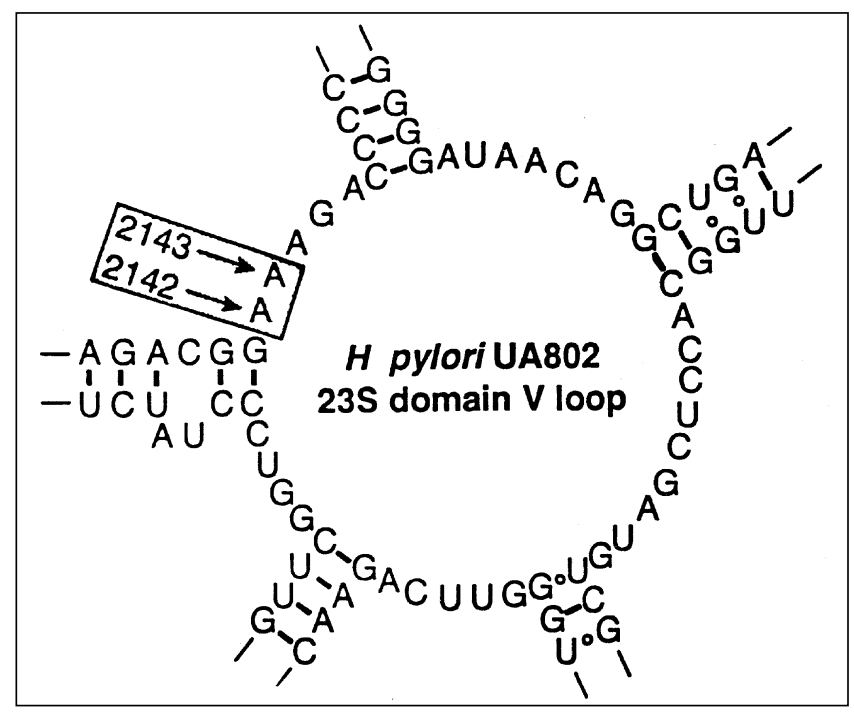

Figure 2) $V$ region of the 23S rRNA subunit of Helicobacter pylori. Transition base substitutions at positions 2142 and/or at 2143 are responsible for clarithromycin resistance. Reproduced with permission from reference 7

with MICs exceeding $64 \mathrm{mg} / \mathrm{L}$ and to be associated with treatment failure (32).

\section{METRONIDAZOLE RESISTANCE}

Metronidazole used in combination with other antibiotics and PPIs is a highly effective therapy against $H$ pylori infection $(3,18,20)$. In general, MICs for metronidazolesusceptible $\left(\mathrm{Mtz}^{\mathrm{S}}\right)$ strains range from 0.1 to $4 \mu \mathrm{g} / \mathrm{mL}$. However, metronidazole-resistant $\left(\mathrm{Mtz}^{\mathrm{R}}\right)$ strains exhibit MIC values in excess of $32 \mu \mathrm{g} / \mathrm{mL}$ as measured by both the epsilometer test and agar dilution methods. Numerous studies have demonstrated that metronidazole susceptibility status dramatically influences the outcome of treatment $(3,17,20,33)$. Treatment failure rates as high as $60 \%$ have been reported for $\mathrm{Mtz}^{\mathrm{R}}$ strains (34).

Metronidazole and other nitroimidazoles are prodrugs because they are biologically inactive until activated by the proper enzyme or target. The basis for toxicity of metronidazole is its conversion through reduction of the 5 nitrogroup through a series of four-electron transfers to the DNA-damaging agent hydroxylamine (35). Alkylation of DNA by hydroxylamine and other redox-active intermediates of the reduction pathway cause mostly transition base mutations in DNA that lead to single strand breakage. For example, sublethal concentrations of hydroxylamine hydroxylate guanosine bases (8-hydroxyguanosine) lead to mispairing with thymine, and, following DNA replication, guanosine is replaced with adenosine. Although metronidazole is classified as a mutagen based on the Ames test (35), the drug is generally considered safe when given for a short term (36). The action of metronidazole on anaerobic bacteria and protozoa is due to the reduction of metronidazole by the ferredoxin-linked pyruvate and other ketoacid oxidoreductase enzyme complexes (37). Reduced electron carriers such as ferredoxin or flavodoxin directly reduce metronidazole. In addition to mutagenic activity on DNA, reduction of metronidazole functions as an electron sink by removing electrons from normal reoxidation routes that ordinarily would lead to ATP production.

In contrast to anaerobic bacteria, where resistance to metronidazole is rare, in microaerophiles such as $\mathrm{H}$ pylori, $\mathrm{Mtz}^{\mathrm{R}}$ is common. In developed countries, $\mathrm{Mtz} \mathrm{R}^{\mathrm{R}}$ of $\mathrm{H}$ pylori isolates ranges from $10 \%$ to $40 \%$, whereas, in developing countries, resistance can range from $50 \%$ to $100 \%$. In general, $\mathrm{Mtz}^{\mathrm{R}}$ parallels the use of metronidazole for the treatment of unrelated infections in monotherapies that are not sufficient to eradicate $H$ pylori infection. This leads to the selection of populations of $\mathrm{Mtz}^{\mathrm{R}}$ strains, often in sites that are colonized with $\mathrm{Mtz}^{\mathrm{S}}$ variants. Recent studies have shown that isogenic $\mathrm{Mtz}{ }^{\mathrm{S}}$ and $\mathrm{Mtz}{ }^{\mathrm{R}}$ strains coinhabit the stomach of some individuals $(5,38)$.

Goodwin et al (5) recently reported that mutations in a gene encoding an oxygen-insensitive NADPH nitroreductase are responsible for the $\mathrm{Mtz}^{\mathrm{R}}$ phenotype of $\mathrm{H}$ pylori. The gene $r d x A$ was identified by a transformation screen of $\mathrm{Mtz}^{\mathrm{S}} \mathrm{H}$ pylori with cosmids from an $\mathrm{Mtz}^{\mathrm{R}}$ strain and the finding of a cosmid clone that conferred resistance at high frequency. $H$ pylori strains are able to take up DNA naturally from the environment, and, following recombination, DNA coding for $\mathrm{Mtz}^{\mathrm{R}}$ enables the bacterium to grow on media supplemented with metronidazole. Subcloning and DNA sequence analysis identified the $r d x A$ gene that encoded the nitroreductase. Cloning and sequencing of the $r d x A$ gene of a wild type $\mathrm{Mtz}_{z} \mathrm{~S}$ strain revealed that the mutant $\mathrm{H}$ pylori strain contained point mutations that led to premature termination of the polypeptide and a biologically inactive product. Allelic exchange mutagenesis achieved through homologous recombination with a chloramphenicol resistance $\left(\mathrm{Cm}^{\mathrm{R}}\right)$ cassette to disrupt the $r d x \mathrm{~A}$ gene of $\mathrm{Mtz}^{\mathrm{S}}$ strain 26695 demonstrated that all colonies selected on the basis of their $\mathrm{Cm}^{\mathrm{R}}$ phenotype were also $\mathrm{Mtz}^{\mathrm{R}}$. Complementation of an $r d x \mathrm{~A}$ mutant allele in an $\mathrm{Mtz}^{\mathrm{R}}$ strain with the wild type $r d x A$ gene provided on a shuttle plasmid that can be maintained in $H$ pylori in trans, conferred $\mathrm{Mtz}_{\mathrm{z}} \mathrm{S}$ to the strain. This finding established that expression of wild type $\mathrm{rdxA}\left(\mathrm{Mtz}^{\mathrm{S}}\right)$ is a dominant phenotype. Taken together, these results indicate that mutations in $r d x A$ are both necessary and sufficient to confer high level metronidazole resistance to $H$ pylori.

$\mathrm{RdxA}$ is a member of the classical nitroreductases (CNRs) found in many bacterial species; however CNRs are perhaps best studied in Salmonella typhimurium, E coli and related Gram-negative organisms. Interestingly, it is the CNR of $S$ typhimurium that is responsible for reducing nitroaromatic compounds to toxic, mutagenic and carcinogenic compounds in the Ames test (35). Null mutations in the gene encoding CNR render the $S$ typhimurium strain resistant to the mutagenic effects of nitroaromatic compounds. A comparison of $\mathrm{RdxA}$ with $\mathrm{CNR}$ homologues (Table 1 ) shows amino acid identities of $25 \%$ to $30 \%$ with similarities approaching $50 \%$. Nitroreductases generally reduce nitroaromatic compounds containing 4 or 5 nitro- 
TABLE 1

Similarity of RdxA of Helicobacter pylori to other classical nitroreductases

\begin{tabular}{lccc}
\hline $\begin{array}{l}\text { Bacterial } \\
\text { species }\end{array}$ & Protein & $\begin{array}{c}\text { Percentage } \\
\text { identity }\end{array}$ & $\begin{array}{c}\text { Percentage } \\
\text { similarity }\end{array}$ \\
\hline $\begin{array}{c}\text { Haemophilus } \\
\text { influenzae }\end{array}$ & $\mathrm{NfsB}$ & 25 & 48 \\
$\begin{array}{c}\text { Enterobacter } \\
\text { cloaceae }\end{array}$ & $\mathrm{NfnB}$ & 30 & 50 \\
$\begin{array}{c}\text { Salmonella } \\
\text { typhimurium }\end{array}$ & $\mathrm{Cnr}$ & 30 & 50 \\
$\begin{array}{c}\text { Escherichia coli } \\
\text { Dfss }\end{array}$ & $\mathrm{Nfs}$ & 49 \\
\hline
\end{tabular}

Data from reference 5

-groups as well as quinones that contain no nitro-group (39).

In general, the CNRs studied from various bacteria exhibit poor specificity for metronidazole. For this reason, facultative anaerobes and aerobes are resistant to metronidazole. What is unique about the nitroreductase of $H$ pylori is its ability to use metronidazole at a higher efficiency than what has been found for other CNRs. RdxA differs from other nitroreductases in both isoelectric point (7.9 versus 4.5 for CNRs) and in cysteine content (six residues in $\operatorname{RdxA}$ versus one or two for CNRs) (5). Therefore, $\mathrm{RdxA}$ may contain an active centre different from that found in CNRs, which may contribute to its lower redox potential and specificity for metronidazole.

Expression of $r d x A$ from a high copy plasmid in $E$ coli has been shown to render the bacterium susceptible to metronidazole ( 10 to $30 \mu \mathrm{g} / \mathrm{mL}$ ) in contrast to controls exhibiting MIC values in excess of $500 \mu \mathrm{g} / \mathrm{mL}$ (5). By using this assay, where the $r d x A$ genes from both $\mathrm{Mtz}^{\mathrm{R}}$ and $\mathrm{Mtz}^{\mathrm{S}}$ strains were cloned into a high copy plasmid and screened for activity in $\mathrm{E}$ coli, $r d x A$ genes from all of the $\mathrm{Mt}^{\mathrm{R}}$ strains tested were unable to render $E$ coli sensitive to metronidazole. In contrast, all $r d x A$ genes from $\mathrm{Mtz}{ }^{\mathrm{S}}$ strains rendered $E$ coli sensitive to metronidazole. Using this assay, Goodwin et al (5) examined matched pairs of $\mathrm{H}$ pylori strains isolated from a single individual in whom one strain was $\mathrm{Mtz}$ and the isogenic member of the pair was $\mathrm{Mtz}^{\mathrm{R}}$. In all cases, the $\mathrm{Mtz}^{\mathrm{R}} r d x \mathrm{~A}$ amplicon had no effect on the pattern of resistance to metronidazole when cloned into $\mathrm{E}$ coli (5). In contrast, the $r d x A$ allele from each of the $\mathrm{Mtz}$ members of the pair rendered $E$ coli susceptible to metronidazole. When sequenced, the $r d x A$ genes from all $\mathrm{Mt}^{\mathrm{R}}$ strains contained transition base mutations that result in amino acid substitutions that render the nitroreductase products inactive (Table 2 ). These studies established that mutations in $r d x A$, rather than the acquisition of DNA from unrelated strains, are responsible for the $\mathrm{Mtz}^{\mathrm{R}}$ phenotype of the strains tested.
TABLE 2

Types of point mutations and amino acid substitutions in matched pairs of metronidazole-resistant and metronidazole-sensitive strains

\begin{tabular}{|c|c|c|c|c|c|}
\hline \multirow[b]{2}{*}{$\begin{array}{l}\text { Strain } \\
\text { pair }\end{array}$} & \multicolumn{4}{|c|}{ Mutation } & \multirow[b]{2}{*}{$\begin{array}{l}\text { Amino acid } \\
\text { substitution }\end{array}$} \\
\hline & $\mathbf{A} \rightarrow \mathbf{G}$ & $\mathrm{C} \rightarrow \mathrm{T}$ & Transversion & Codon* & \\
\hline H2amt & 1 & & & 200 & Arg $\rightarrow$ Gly \\
\hline B1amt & 3 & & & 47,143 & Tyr $\rightarrow$ Cys \\
\hline $21 \mathrm{cmt}$ & 2 & & & 50,63 & Gln $\rightarrow$ Arg \\
\hline $12 \mathrm{mtz}$ & 1 & & & 80 & $\mathrm{Ala} \rightarrow \mathrm{Thr}$ \\
\hline 10amt3 & 1 & 1 & 1 & 143 & Gly $\rightarrow$ Val \\
\hline $439 / 500^{\dagger}$ & 8 & 15 & 4 & & (8 AA changes) \\
\hline
\end{tabular}

*Codon where base substitution leads to amino acid change; ${ }^{\dagger}$ Comparison of divergence in rdxA of unrelated Helicobacter pylori strains 439 and 500. The number of amino acid changes between these strains is listed. A Adenine; AA Amino acid; Ala Alanine; Arg Argenine; C Cytosine; Cys Cysteine; G Guanine; Gln Glutamine; Gly Glycine; T Thymine; Thr Threonine; Tyr Tyrosine; Val Valine. Data from reference 5

\section{METRONIDAZOLE INCREASES THE MUTATION FREQUENCY AND MAY BE RESPONSIBLE FOR MULTIPLE ANTIBIOTIC RESISTANCE}

One unanswered question related to the use of metronidazole for the treatment of a wide range of infections is whether reduction of metronidazole leads to mutations in genes other than $\operatorname{rdx} \mathrm{A}$, such as those involved in antibiotic resistance. To begin testing this hypothesis, an assay, originally developed by Jeffery Miller (40), was adopted to assess the frequency of transition (adenine $\rightarrow$ guanine or thymine $\rightarrow$ cytosine, and vice versa) and transversion base mutations (guanine $\rightarrow$ thymine). In this assay, mutations are introduced into a common codon (461) of the lacZ gene of $E$ coli that render the lac operon inactive (betagalactosidase negative). As a result, mutations leading to restoration of the codon can be demonstrated by expression of beta-galactosidase activity. For these studies, $r d x A$ was introduced on a plasmid into each of the five tester $E$ coli strains containing different base substitutions in codon 461, and then the mutation frequency was assessed for each position following growth in the presence of metronidazole. It was previously shown (5) that the vast majority of mutations in $r d x A$ genes are transition base mutations of the kind predicted by the action of hydroxylamine on DNA (41). In contrast, transversion mutations are relatively rare and occur at a low frequency. The frequency of transition base mutations scored was a function of the metronidazole concentration. Concentrations of metronidazole of 5 and $10 \mu \mathrm{g} / \mathrm{mL}$ increased the transition base mutation frequency up to 300-fold. Higher levels of metronidazole were shown to cause a substantial increase in the frequency of transversions (unpublished data), which may be due to a more complex DNA repair and mutator system in $E$ coli (40). At 5 to $10 \mu \mathrm{g} / \mathrm{mL}$ of metronidazole, the viability of $E$ coli was diminished by $80 \%$, a further indication of the toxicity generated by the 
enzymatic conversion of metronidazole to mutagenic products such as hydroxylamine. Hydroxylamine is commonly used to generate transition base mutations. Metronidazole reduction by $\mathrm{RdxA}$ also increases the frequency of rifampicin-resistant $E$ coli mutants, which are also due to point mutations.

Clarithromycin resistance is more difficult to score in $E$ coli strains because, unlike the two copies of the $23 \mathrm{~S}$ rRNA genes in $\mathrm{H}$ pylori, E coli contains six or more copies. To obtain resistance to clarithromycin, mutations would be required in all copies, a rather rare event. Many studies have examined the effect of sublethal concentrations of antibiotics on the selection of resistant phenotypes (14). However, based on findings that $\mathrm{RdxA}$ can reduce metronidazole to toxic and mutagenic products that increase mutation frequency, future experiments should examine $H$ pylori strains treated with sublethal concentrations of metronidazole for the development of resistance to clarithromycin. These findings would serve as a model for the potential in vivo development of multiple drug resistance.

Antibiotic resistance of $\mathrm{H}$ pylori is mutation based and does not involve the acquisition of antibiotic resistance genes from other bacterial species. The correlation between metronidazole use in a community and the incidence of metronidazole resistance in the $H$ pylori population in that community can be explained by the action of the NADPH nitroreductase, which activates metronidazole to mutagenic intermediates that introduce transition base substitutions at random into the genome. Because metronidazole is commonly used in monotherapy for the treatment of a wide range of diseases and this monotherapy is not successful in eradicating $H$ pylori infection, it is not too surprising that resistant strains arise. $\mathrm{Mtz}^{\mathrm{R}}$ status of $\mathrm{H}$ pylori strains does not alter the fitness of the strains to produce disease. Consequently, $\mathrm{Mtz}^{\mathrm{R}} \mathrm{sib}$ lings are not selected against once metronidazole selection is removed. Whether injudicious treatment with metronidazole leads to mutations in other genes that render a strain resistant to other antibiotics including clarithromycin remains to be determined.

Alternative drugs that ultimately might replace metronidazole include furazolidone and nitazoxanide. The latter compound is a nitrothiazole, which, in preliminary studies, was reported to have an $85 \%$ success rate as a monotherapy (unpublished data). Both drugs may have a mechanism of action similar to metronidazole's, though their higher redox potentials may enable these agents to be activated by reductases other than $\mathrm{RdxA}$ and, therefore, to show efficacy against $\mathrm{Mtz}^{\mathrm{R}}$ strains.

ACKNOWLEDGEMENTS: The author thanks Diane Taylor for helpful suggestions and for providing Figure 1 and Sander van Zanten for critical reading of the manuscript. Portions of the studies described in this review were supported by the MRC Partnership Program with Astra Pharma Canada, ROMARK Inc and an NSERC Strategic Grant.

\section{REFERENCES}

1. Dunn BE, Cohen H, Blaser MJ. Helicobacter pylori. Clin Microbiol Rev 1997;10:720-41.

2. Taylor DN, Parsonnet J. Epidemiology and natural history of $H$ pylori infections. In: Blaser MJ, Smith PF, Ravdin J, Greenberg H, Guerrant RL, eds. Infections of the Gastrointestinal Tract. New York: Raven Press, 1995:551-64.

3. Veldhuyzen van Zanten SJO, Sherman PM, Hunt RH. Helicobacter pylori: new developments and treatments. Can Med Assoc J 1997;156:1565-74.

4. Correa P, Fox J, Fontham E, et al. Helicobacter pylori and gastric carcinoma. Serum antibody prevalence in populations with contrasting cancer risks. Cancer 1990;66:2569-74.

5. Goodwin A, Kersulyte D, Sisson G, van Zanten SJO, Berg DE, Hoffman PS. Metronidazole resistance in Helicobacter pylori is due to null mutations in a gene $(r d x A)$ that encodes an oxygen-insensitive NADPH nitroreductase. Mol Microbiol 1998;28:383-93.

6. Moore RA, Beckthold B, Wong S, Kureishi A, Bryan LE. Nucleotide sequence of the gyrA gene and characterization of ciprofloxacin- resistant mutants of Helicobacter pylori. Antimicrob Agents Chemother 1995;39:107-11.

7. Taylor DE, Ge Z, Purych D, Lo T, Hiratsuka K. Cloning and sequence analysis of two copies of a $23 \mathrm{~S}$ rRNA gene from Helicobacter pylori and association of clarithromycin resistance with 23S rRNA mutations. Antimicrob Agents Chemother 1997;41:2621-8.

8. Versalovic, J, Shorttridge D, Kibler K, et al. Mutations in 23S rRNA are associated with clarithromycin resistance in Helicobacter pylori. Antimicrob Agents Chemother 1996;40:477-80.

9. Wang Y, Roos P, Taylor DE. Transformation of Helicobacter pylori by chromosomal metronidazole resistance and by a plasmid with a selectable chloramphenicol resistance marker. J Gen Microbiol 1993;139:2485-93.

10. Tomb J-F, White O, Kerlavage AR, et al. The complete genome sequence of the gastric pathogen Helicobacter pylori. Nature 1997;388:539-47.

11. Alm RA, Ling LS, Moir DT, et al. Genomic-sequence comparison of two unrelated isolates of the human gastric pathogen Helicobacter pylori. Nature 1999;397:176-80.

12. Coudron PE, Stratton CW. Use of time-kill methodology to assess antimicrobial combinations against metronidazole-susceptible and metronidazole-resistant strains of Helicobacter pylori. Antimicrob Agents Chemother 1995;39:2641-4.

13. Goddard AF, Jessa MJ, Barrett DA, et al. Effect of omeprazole on the distribution of metronidazole, amoxicillin, and clarithromycin in human gastric juice. Gastroenterology 1996;111:358-67.

14. Taylor DE. Antibiotic resistance mechanisms of Helicobacter pylori.

In: Moran AP, O’Morain A, eds. Pathogenesis and Host Response in Helicobacter pylori Infections. New Jersey: Normed Verlag, 1997:101-9.

15. Jonkers D, Stobberingh E, Stockbrugger R. Omeprazole inhibits growth of gram-positive and gram-negative bacteria including Helicobacter pylori in vitro. J Antimicrob Chemother 1996;37:145-50.

16. Marshall BJ. Treatment strategies for Helicobacter pylori infection. Gastroenterol Clin North Am 1993;22:183-98.

17. Salcedo JA, Al-Kawas F. Treatment of Helicobacter pylori infection. Arch Intern Med 1998;158:842-51.

18. Megraud F. Resistance of Helicobacter pylori to antibiotics. Aliment Pharmacol Ther 1997;11(Suppl 1):43-53.

19. Haas CE, Nix DE, Schentag JJ. In vitro selection of resistant Helicobacter pylori. Antimicrob Agents Chemother 1990;34:1637-41.

20. Veldhuyzen van Zanten S, Hunt RH, Cockeram A, et al. Adding once-daily omeprazole $20 \mathrm{mg}$ to metronidazole/amoxicillin treatment for Helicobacter pylori gastritis: A randomized, double-blind trial showing the importance of metronidazole resistance. Am J Gastroenterol 1998;93:5-10.

21. Huesca MS, Borgia S, Hoffman PS, Lingwood CA. Acidic pH changes 1 receptor binding specificity of Helicobacter pylori: a binary adhesion mode in which surface heat shock (stress) proteins mediate sulfatide recognition in gastric colonization. Infect Immun 1996;64:2643-8. 
22. Maxwell A. The molecular basis of quinolone action. I Antimicrob Chemother 1992;30:409-14.

23. Wang Y, Huang WM, Tavlor DE. Cloning and nucleotide sequence of the Campylobacter jejuni gyrA gene and characterization of quinolone resistance mutations. Antimicrob Agents Chemother 1993:37:457-63.

24. Marshall BJ, Goodwin CS, Warren JR, et al. A prospective double-blind trial of duodenal ulcer relapse after eradication of Campylobacter pylori. Lancet 1988;i1:1437-42.

25. Mahony DE, Lim-Morrison S, Bryden L, et al. Antimicrobial activities of synthetic bismuth compounds against Clostridium difficile. Antimicrob Agents Chemother 1999;43:582-8.

26. Beil W, Bierbaum S, Sewing KF. Studies on the mechanism of action of colloidal bismuth subcitrate. I. Interaction with sulfhydryls. Pharmacology 1993;47:135-40.

27. Peterson WL, Graham DY, Marshall B, et al. Clarithromvcin as monotherapy for eradication of Helicobacter pylori: a randomized double blind trial. Am J Gastroenterol 1993;88:1860-4.

28. Chiba N, Wilkinson JM, Hunt RH. Clarithromycin or amoxicillin dual and triple therapies in Helicobacter pylori eradication: a meta-analysis. Gut 1995;3:A31. (Abst)

29. Cayla R, Zerbib F, Talbi P, et al. Pre and post treatment clarithromycin resistance of Helicobacter pylori strains: a key factor of treatment failure. Gut 1995;37(Suppl 1):A55. (Abst)

30. Tompkins DS, Perkin I, Smith C. Failed treatment of Helicobacter pylori infection associated with resistance to clarithromycin. Helicobacter $1997 ; 2: 185-7$.

31. Stone GG, Shortridge D, Flamm RK, et al. Identification of a $23 \mathrm{~S}$ rRNA gene mutation in clarithromycin-resistant Helicobacter pylori . Helicobacter 1996;1:227-8.

32. Versalovic J, Osato MS, Spakovsky K, et al. Point mutations in the $23 \mathrm{~S}$ rRNA gene of Helicobacter pylori associated with different levels of clarithromvcin resistance. I Antimicrob Chemother $1997 ; 40 \div 283-6$.

33. Buckley MJ, Xia HX, Hyde DM, Keane CT, O'Morain CA. Metronidazole resistance reduces efficacy of triple therapy and leads to secondary clarithromycin resistance. Dig Dis Sci $1997: 42: 2111.5$.

34. Adamek RJ, Suerbaum S, Pfaffenbach B, Opferkuch W. Primary and acquired Helicobacter pylori resistance to clarithromycin, metronidazole, and amoxicillin - influence on treatment outcome. Am J Gastroenterol 1998;93:386-9.

35. Lindmark DG, Muller M. Antitrichomonad action, mutagenicity, and reduction of metronidazole and other nitroimidazoles. Antimicrob Agents Chemother 1976;10:476-82.

36. Falagas ME, Walker AM, Jick H, Ruthazer R, Griffith J, Snydman DR. Late incidence of cancer after metronidazole use: A matched metronidazole user/nonuser study. Clin Infect Dis 1997;26:384-8.

37. Lockerby DL, Rabin HR, Laishley EJ. Role of the phosphoroclastic reaction of Clostridium pasteurianum in the reduction of metronidazole. Antimicrob Agents Chemother 1985;27:863-7.

38. Berg DE, Gilman RH, Lelwala-Guruge J, et al. Helicobacter pylori populations in Peruvian patients. Clin Infect Dis $1997 ; 25: 996-1002$.

39. Bryant C, Deluca M. Purification and characterization of an oxygen-insensitive NAD(P)H nitroreductase from Enterobacter cloacae. J Biol Chem 1991;266:4125-30.

40. Nghiem Y, Cabrera M, Cupples CG, Miller JH. The mutY gene: A mutator locus in Escherichia coli that generates $\mathrm{GC} \rightarrow \mathrm{TA}$ transversions. Proc Natl Acad Sci USA 1988;85:2709-13.

41. Yamanoto K, Kawanishi S. Site-specific DNA damage and 8-hydroxydeoxyguanosine formation by hydroxylamine and 4-hydroxaminoquinoline 1 oxide in the presence of $\mathrm{Cu}(\mathrm{II})$ : role of active oxygen species. Carcinogenesis $1993 ; 14: 1397-401$. 


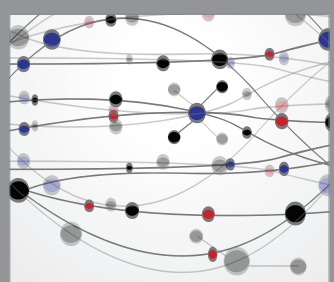

The Scientific World Journal
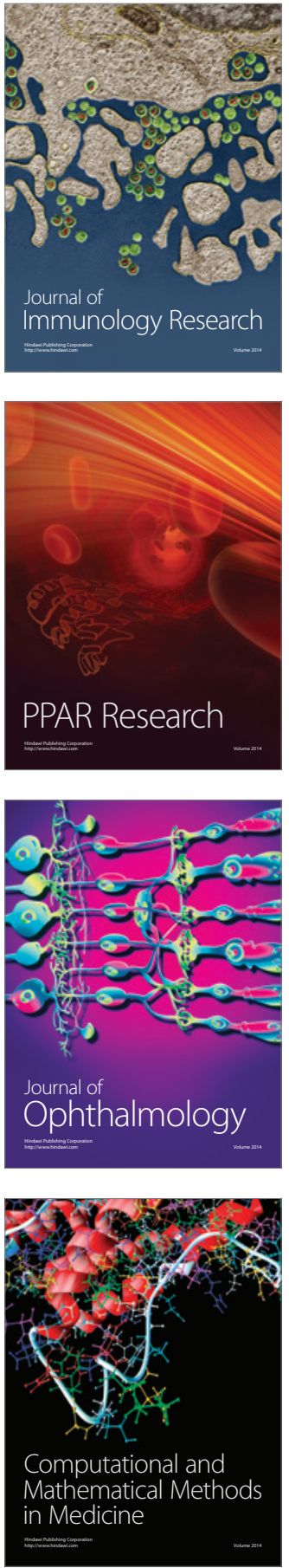

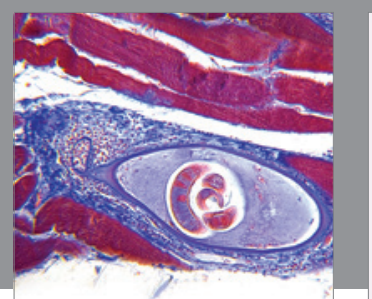

Gastroenterology Research and Practice

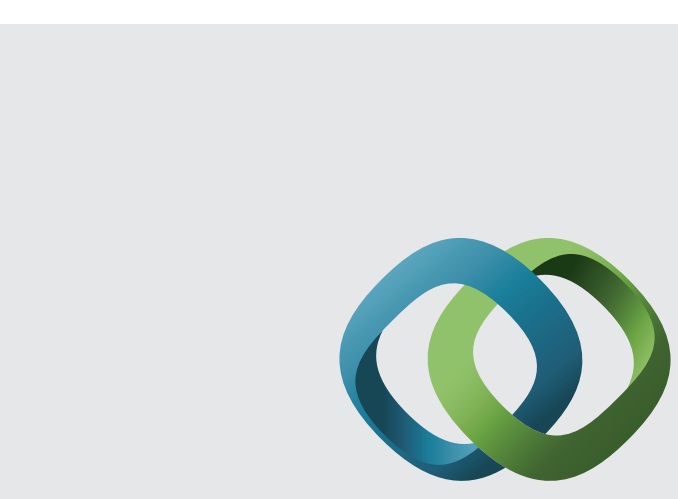

\section{Hindawi}

Submit your manuscripts at

http://www.hindawi.com
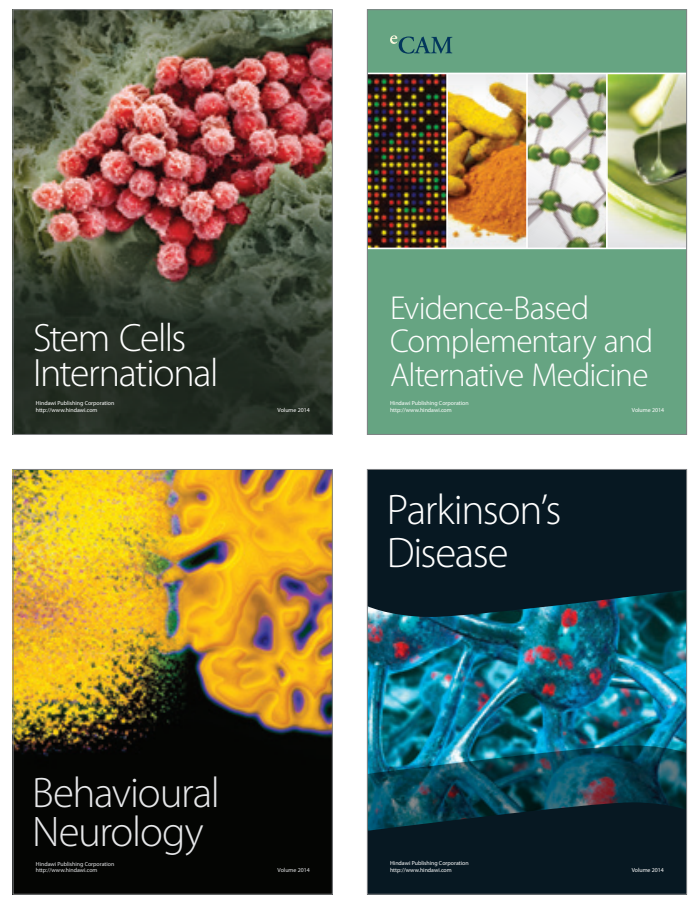
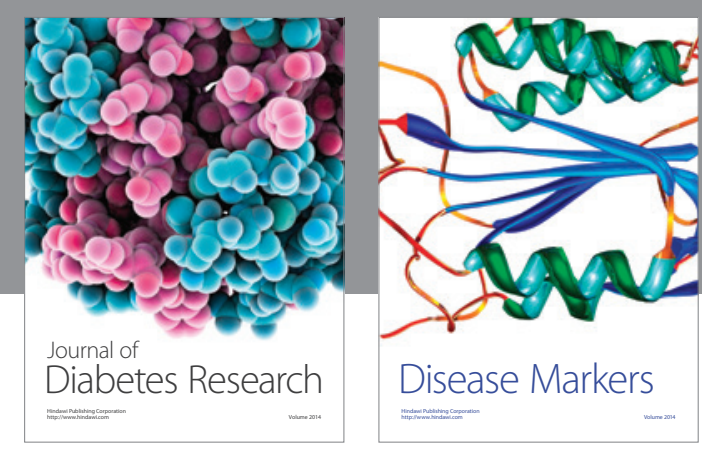

Disease Markers
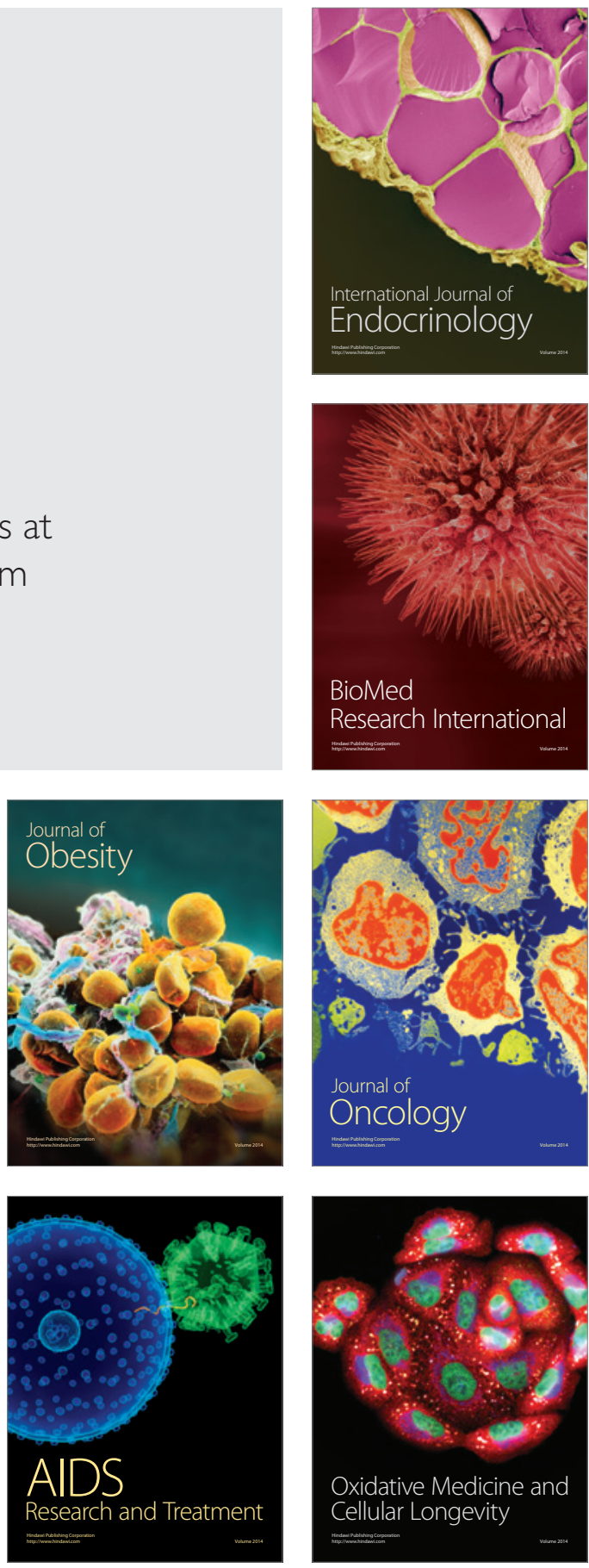